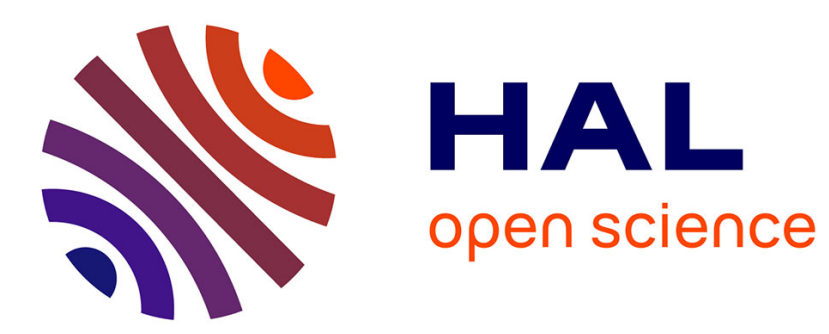

\title{
Influence of the Structure in Magnetic Properties in Co-P Electrodeposited Amorphous Alloys
}

\author{
A. García-Arribas, M. Fdez-Gubieda, J. Barandiarán, J. Herreros
}

\section{To cite this version:}

A. García-Arribas, M. Fdez-Gubieda, J. Barandiarán, J. Herreros. Influence of the Structure in Magnetic Properties in Co-P Electrodeposited Amorphous Alloys. Journal de Physique IV Proceedings, 1997, 7 (C2), pp.C2-997-C2-998. 10.1051/jp4:19972113 . jpa-00255171

\section{HAL Id: jpa-00255171 https://hal.science/jpa-00255171}

Submitted on 1 Jan 1997

HAL is a multi-disciplinary open access archive for the deposit and dissemination of scientific research documents, whether they are published or not. The documents may come from teaching and research institutions in France or abroad, or from public or private research centers.
L'archive ouverte pluridisciplinaire HAL, est destinée au dépôt et à la diffusion de documents scientifiques de niveau recherche, publiés ou non, émanant des établissements d'enseignement et de recherche français ou étrangers, des laboratoires publics ou privés. 


\title{
Influence of the Structure in Magnetic Properties in Co-P Electrodeposited Amorphous Alloys
}

\author{
A. García-Arribas, M.L. Fdez-Gubieda*, J.M. Barandiarán and J. Herreros** \\ Departamento de Fisica, Universidad de Oviedo, Av. de Calvo Sotelo s/n., 33007 Oviedo, Spain \\ * Departamento de Electricidad y Electrónica, Universidad del País Vasco, Apartado 644, 48080 Bilbao, \\ Spain \\ ** Departamento de Física Aplicada II, Universidad del País Vasco, Apartado 644, 48080 Bilbao, Spain
}

\begin{abstract}
The short range order of a series of $\mathrm{Co}_{100-\mathrm{x}} \mathrm{P}_{x}(17<\mathrm{x}<26)$ amorphous alloys prepared by electrodeposition is studied by EXAFS. The structural parameters as coordination numbers and interatomic distances have been found to vary significantly with $P$ concentration. This behaviour contrasts with that of $F e-P$ alloys where the environment of the Fe atoms does not change appreciably with composition. The structural differences between both systems are related with clear differences in the magnetic properties, most of all in the dependence on concentration of the Curie temperature.
\end{abstract}

\section{INTRODUCTION}

The fundamental magnetic properties such as saturation magnetization $J_{s}$ and Curie temperature $T_{c}$ are mainly determined by the local atomic configuration. For the existence of magnetic ordering it is not necessary to have translational symmetry. This is the case in the metallic glasses where only a short range order which involves the first coordination shell exists. To analyze the structure of these systems is then necessary to use techniques which are sensitive to the local arrangement of atoms, like EXAFS. Binary amorphous systems such as Fe-P or Co-P are suitable to study the correlation between the structure and the magnetic properties due to the small number of components. Besides, a great amount of data about the magnetic properties of both systems is available in a wide range of concentrations[1]. It is specially interesting to compare both systems. They should be similar attending to the nature of their components. However there are striking differences in the magnetic behaviour, mostly in the composition dependence of the Curie temperature which remains nearly constant in Fe-P while decreases linearly with $P$ content in Co-P [2].

We have recently analyzed [3] the structure of Fe-P and its relation with the magnetic properties. In this work we present a complete EXAFS study of the short range order in the Co-P amorphous system. Some studies on single samples are available in the literature $[4,5]$ but it is necessary to sweep a wide range of compositions to correlate the results with the magnetic properties.

\section{EXPERIMENTAL}

Samples $20 \mu \mathrm{m}$ thick were electrodeposited from aqueous solutions using a standard bath composition [6]. The composition of the samples was determined by energy dispersive analysis in a scanning microscope with a maximum estimated error of $1 \%$ at. They were checked to be in a fully amorphous state by $\mathrm{X}$-ray diffraction.

Room temperature X-ray absorption spectra were obtained at Daresbury Laboratory (UK.). Co-K edges were measured in the usual transmission geometry using a Si(111) double crystal monochromator. The P-K edge was measured in some samples in the total electron yield geometry and using a InSb monochromator. The presence of the Sulphur edge due to vacuum chamber contamination restrict seriously the usefulness of $P$ edge spectra.

\section{DATA ANALYSIS}

Normalized EXAFS functions $\chi(k)$ were obtained using a standard procedure [7]. The atomic absorption above the edge was fitted using a three cubic spline in the $k$ range $2 \AA^{-1} \leq k \leq 12 \AA^{-1}$. The origin of the $k$ space was taken at the inflection point of the absorption edge. $\mathrm{Co}_{100-x} \mathrm{P} \times$ EXAFS functions obtained in this way are reported in Fig. 1 (a). As expected, the amplitude of the spectra differs mainly in the low $\mathrm{k}$ values, due to the great scattering power of $\mathrm{P}$ atoms in the range $3 \AA^{-1} \leq k \leq 5 \AA^{-1}$. Fourier transform of $\mathcal{X}(k)$ was performed with a $k^{3}$ weight and a Hanning window function in the $\mathrm{k}$ range $2 \AA^{-1} \leq k \leq 12 \AA^{-1}$. Finally, the inverse Fourier transform was performed on the main peak.

In the analysis of the filtered spectrum we have accounted for the asymmetry in the radial distribution function, characteristic of the metallic glasses, by introducing the expression proposed by De Crescenzi [8], leading to the following expression which was used for the fitting:

$$
k \chi(k)=\sum_{j} \frac{N_{j} f_{j}(k, \pi)}{R_{j}^{2}} \frac{e^{-2 \Gamma_{j} / k} e^{-2 \sigma_{j}^{2} k^{2}}}{\sqrt{1+4 k^{2} \sigma_{D_{j}}^{2}}} \sin \left[2 k R_{j}+\tan ^{-1}\left(2 k \sigma_{D_{j}}\right)+\Phi_{j}\right]
$$



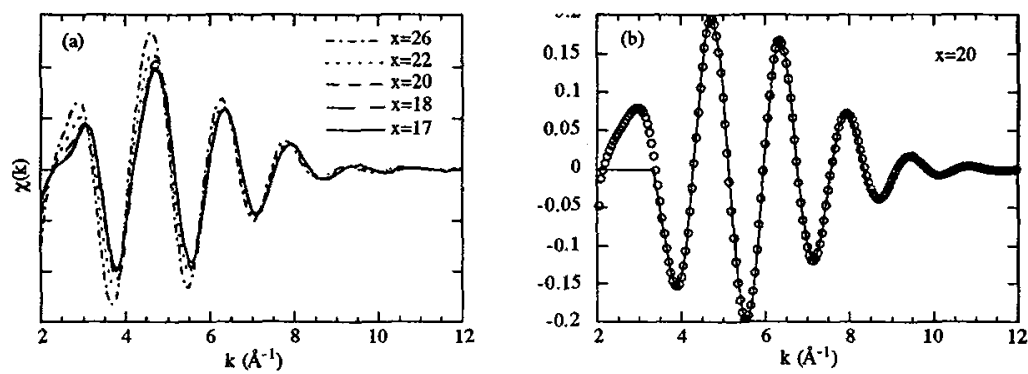

Figure 1 (a): Co-K edge EXAFS spectra for $\mathrm{Co}_{100-\mathrm{x}} \mathrm{P}_{\mathrm{x}}$ amorphous alloys. (b): Fourier filtered signal (dots) and best fit (line).

Here, $R_{j}$ is the closest distance of $\mathrm{j}$-type atoms to the absorber and $\sigma_{D j}$ is the root mean square of the distribution of distances. It represents the structural disorder around each atom site. The average first neighbour distance is then $\bar{R}_{j}=R_{j}+\sigma_{D j}$

Model Functions were built by a linear combination of $\mathrm{Co}-\mathrm{Co}$ and $\mathrm{Co}-\mathrm{P}$ pairs for the $\mathrm{Co}-\mathrm{K}$ edge. Theoretical amplitudes and phase shifts were taken from FEEF3 codes [9]. Scattering factors were optimized using fcc Co and $\mathrm{Fe}_{2} \mathrm{P}$ as reference compounds.

\section{RESULTS AND DISCUSSION}

Our analysis have as starting point the results obtained by neutron diffraction by Sadoc et al. [4] in a sample of composition $\mathrm{Co}_{81} \mathrm{P}_{19}$ and by Lagarde et al. [5] in a sample of approximate composition $\mathrm{Co}_{80} \mathrm{P}_{20}$ using the EXAFS technique. The average distances reported by these authors are $\bar{R}_{C_{0} C_{0}}=2.54 \AA, \bar{R}_{C o P}=2.32 \AA$ and $\bar{R}_{C_{o c o}}=2.47 \AA, \bar{R}_{C o P}=2.29 \AA$ respectively. The latter authors also use an asymmetrical distribution function and give values for the closest distances $R_{C_{o} C_{o}}=2.43 \AA$ and $R_{C o P}=2.19 \AA$. The coordination numbers in both cases are $N_{C o C o}=10$ and $N_{C o P}=1.5$ approx. Our results, presented in Table I, show good agreement with these data in the coincident samples, except in the Co-Co distances reported in [5]. The whole set of parameters obtained for our samples shows a clear increase of the closest distances $R_{C_{o} C_{o}}$ with the $\mathrm{P}$ content whereas the associated structural disorder $\sigma_{D_{C o} C_{o}}$ decreases. The average distances $\bar{R}_{C o C_{o}}$ increase only slightly (inside the experimental error). The distances $\mathrm{Co}-\mathrm{P}$ remain nearly constant due to the covalent nature of the bond. The coordination numbers are affected by greater errors but they follow the stoichiometric relation of the samples, increasing $N_{C o C o}$ and decreasing $N_{C o P}$ when the Co content increases. The results obtained in the P.edge (not reported here) confirm these results for the samples where this analysis was possible.

The most important feature of these results is that both closest distances between metallic atoms and coordination numbers vary appreciably with the increasing $P$ concentration. This behaviour is in clear contrast with that of the Fe-P system where both parameters remain nearly unchanged. So the differences in the magnetic properties reported for these systems are shown to correlate with concomitant changes in the short range order.

\section{Acknowledgments}

This work has been partially supported by UPV/EHU under project No. UPV 224.310-EA 088/95. We thank the Daresbury Laboratory for Synchrotron measurements facility and the P.U.L.S. group at Frascati Laboratory for the EXAFS programs.

Table I: Values of the structural parameters obtained in the fittings of the Co-K edges for the $\mathrm{Co}_{100-\mathrm{x}} \mathrm{P}_{\mathrm{x}}$ samples.

\begin{tabular}{cccccccccc}
\hline$x$ & $N_{C o C o}$ & $R_{C o C o}(\AA)$ & $\sigma_{D_{C o C o}}(\AA)$ & $\bar{R}_{C o C o}(\AA)$ & $N_{C o P}$ & $R_{C o P}$ & $\sigma_{D_{C o P}}(\AA)$ & $\vec{R}_{C o P}(\AA)$ \\
\hline 26 & $9.0(9)$ & $2.430(9)$ & $0.13(2)$ & $2.56(3)$ & $2.7(6)$ & $2.10(2)$ & $0.18(5)$ & $2.28(7)$ \\
22 & $9.8(7)$ & $2.410(6)$ & $0.15(1)$ & $2.56(3)$ & $2.5(4)$ & $2.10(1)$ & $0.22(4)$ & $2.31(5)$ \\
20 & $10.1(7)$ & $2.390(6)$ & $0.15(1)$ & $2.54(7)$ & $2.2(4)$ & $2.09(2)$ & $0.24(5)$ & $2.33(7)$ \\
18 & $10.0(6)$ & $2.390(5)$ & $1.16(1)$ & $2.55(6)$ & $2.2(3)$ & $2.10(1)$ & $0.20(9)$ & $2.2(1)$ \\
17 & $10.0(9)$ & $2.387(8)$ & $1.16(1)$ & $2.54(2)$ & $2.0(7)$ & $2.08(3)$ & $0.25(9)$ & $2.3(1)$ \\
\hline \hline
\end{tabular}

\section{References}

[1] K. Hüller, G. Dietz, R. Hausmann, and K. Kölpin, J. Magn. Magn. Mater. 53 (1985) 103.

[2] M. Takahashi and M. Koshimura, Jpn. J. Appl. Phys. 16 (1977) 1711.

[3] A. García-Arribas, M.L. Fdez-Gubieda, I. Orue, J.M. Barandiarán, J. Herreros, and F. Plazaola, Phys. Rev. B 52 (1995) 12805.

[4] J.F. Sadoc and J. Dixmier, Mater. Sci. Eng. 23 (1976) 187.

[5] P. Lagarde, J. Rivory, and G. Vlaic, J. Non-Cryst. Solids 57 (1983) 275.

[6] A. Brenner, Electrodeposition of alloys (Academic Press, New York, 1963)

[7] B. Lengeler and P. Eisenberger, Phys. Rev. B 21 (1980) 4507.

[8] M. De Crescenzi, A. Baltzatori, F. Comin, L. Incoccia, S. Mobilio, and N. Motta, Solid State Commun. 37 (1981) 921.

[9] J. Mustre de Leon, J.J. Rehr, R.C. Albers, and S.I. Zabinsky, Phys. Rev. B 44 (1991) 4146. 